\title{
SABERES DOCENTES: DIFERENTES TIPOLOGIAS E CLASSIFICAÇÕES DE UM CAMPO DE PESQUISA
}

\author{
Cecília Borges*
}

\begin{abstract}
RESUMO: O objetivo deste artigo é apresentar algumas das diferentes tipologias e classificações das pesquisas sobre o ensino, os professores e seus saberes. Três sínteses críticas importantes são analisadas. Elas propõem uma categorização dos estudos sobre esse tema e colocam em evidência tanto a diversidade das correntes de pesquisa como os contextos teóricos e metodológicos nos quais estas foram sendo produzidas. Como conclusão, são discutidos os limites e possibilidades desta literatura.
\end{abstract}

Palavras-chave: saberes docentes, conhecimento, ensino, formação de professores.

\section{Introdução}

Pelo menos nos últimos 20 anos (Houston et al., 1990; Sikula, 1996), a partir de concepções e orientações variadas, milhares de pesquisas sobre o ensino, os docentes e seus saberes têm sido produzidas na América do Norte, na Europa e em diferentes países de cultura anglo-saxônica (Tardif, Lessard e Gauthier, 1998). E, a cada ano, é publicado um número extraordinário de obras e artigos sobre esse tema, em diversos lugares no mundo todo. Nos Estados Unidos, os grandes Handbooks aparecem cada vez mais voltados para essa questão, apresentando imensas sínteses de algumas centenas de milhares de artigos das pesquisas em andamento. ${ }^{1}$

Dessa importante e abundante produção de trabalhos focalizando os "saberes" ou "conhecimentos" do professor, ressalta-se a diversi-

\footnotetext{
* Professora no Departamento de Ensino da Universidade Federal de Pelotas (UFPel) e doutoranda em Educação pela Pontifícia Universidade Católica do Rio de Janeiro (PUC-Rio). E-mail: cmborges@rdc.puc-rio.br
} 
dade conceitual e metodológica das pesquisas. Evidentemente, o acúmulo teórico gera uma base suficiente para produzir os trabalhos considerados sínteses, os quais buscam captar as diversidades teóricas e metodológicas das pesquisas, de um lado, ou, segundo critérios específicos, estabelecer agrupamentos, classificações e tipologias, de outro.

As diferentes tipologias e classificações dão uma idéia da diversidade de enfoques e do ecletismo presentes em algumas pesquisas. A diversidade e o ecletismo nada mais são que o reflexo da expansão do campo, no qual os pesquisadores buscam lançar luzes sobre as diferentes facetas, aspectos, características, dimensões etc. que envolvem o ensino e os saberes dos professores. As diferentes tipologias engendradas por alguns pesquisadores, além de contribuírem para organizar o campo, corroboram para identificar sua complexidade e, também, as lacunas ainda não exploradas nos diferentes estudos.

Neste texto, tenho por meta colocar em evidência a diversidade presente nesse campo, apresentando algumas dessas diferentes tipologias e classificações das pesquisas sobre o ensino, sobre a docência e sobre os saberes dos docentes. Inicialmente, é importante assinalar que não pretendo abordar e esgotar todo esse universo de pesquisas; isso demandaria um estudo cuja envergadura assumiria proporções bem maiores do que o pretendido aqui. Ao contrário, meu objetivo é bem mais modesto e, nesse sentido, selecionei alguns trabalhos que fornecem essa visão mais generalizada dos tipos de abordagens que marcaram a pesquisa educacional, julgando que, através deles, estarei pondo em evidência toda uma diversidade de enfoques como, também, oferecendo argumentos em favor da necessidade de se desenvolver uma análise não unívoca e não linear na pesquisa sobre os saberes docentes.

No decorrer de minha exposição, procederei da seguinte forma: primeiro, apresentarei três estudos, escolhidos por sua amplitude, os quais fazem um bom levantamento das pesquisas desenvolvidas sobre o ensino, sobre a docência e sobre os saberes dos docentes, identificando e classificando os tipos de investigação, bem como as diferentes abordagens teórico-metodológicas subjacentes a estas. Em segundo lugar, tratarei de refletir a respeito do problema das tipologias, situando suas contribuições no seio de uma problemática que pode ser identificada em vários países no mundo todo, e cuja amplitude e diversidade traz alguns desafios para a discussão dos saberes docentes atualmente. 


\section{Algumas tipologias e classificações}

Como destaquei na introdução, depois de mais de duas décadas, na América do Norte, o acúmulo teórico no campo educacional é suficiente para ativar o desenvolvimento de sínteses críticas das pesquisas sobre o tema do ensino e do saber dos docentes. Os três trabalhos que apresentarei aqui, de Lee Shulman (1986a), de Daniel Martin (1992) e de Gauthier et al. (1998), correspondem a esse tipo de estudo, no qual seus autores buscam estabelecer diferentes classificações, identificando as diversas abordagens teórico-metodológicas que orientaram e orientam as pesquisas sobre o ensino de um modo geral, sobre a docência mais especificamente e sobre os saberes dos docentes propriamente ditos.

Ainda que se trate do contexto norte-americano, o fato delas apresentarem sínteses consistentes e abrangentes do campo é o motivo de minha escolha. Além disso, mesmo se os estudos sobre o ensino, os docentes e seus saberes são produzidos em vários países, temos que considerar que uma grande massa de pesquisas foi e vem sendo produzida nos EUA, influenciando diversos países, entre eles o Brasil. Uma outra observação a ser feita é que as três sínteses foram produzidas em períodos distintos, estando marcadas pelo contexto social, científico e político no qual foram desenvolvidas e por interesses científicos particulares da parte dos seus autores.

A primeira, de Shulman, é realizada em meados da década de 1980, quando a questão dos saberes dos docentes começava a tornar-se relevante, especialmente após os relatórios apresentados pelo Grupo Holmes (1986) e pelo Carnegie Task Force on Teaching as a Profession (1986), ${ }^{2}$ manifestando o descontentamento geral com a educação americana e, sobretudo, com as faculdades de educação pela má formação dos futuros professores. Sua análise se inscreve em um contexto de crítica à pesquisa desenvolvida até aquele momento e segue, pode-se dizer, os passos iniciados por seus antecessores Gage (1963) e Doyle (1977), cujos trabalhos constituem referências fundamentais em se tratando de uma verdadeira revisão crítica das pesquisas sobre o ensino. Sabe-se, também, que o programa de Shulman, no âmbito dos estudos que ficaram conhecidos entre nós como knowledge base, seguiu produzindo e servindo de referência para as reformas educativas americanas durante toda a década de 1990. Trata-se, portanto, de uma personalidade que tem influenciado não apenas o meio científico acadêmico, mas também o meio político educacional. ${ }^{3}$ Para esta reflexão, considerarei seu trabalho de 1986, uma 
vez que este pode ser considerado como uma referência de base de sua produção posterior e, ao mesmo tempo, uma das sínteses mais importantes para o estudo dos saberes docentes.

A segunda síntese, de Martin (1992), ${ }^{4}$ que tem como foco de estudo declarado identificar a natureza das pesquisas sobre os saberes docentes, é mais recente e vai abarcar um contexto de grande efervescência, no qual a problemática dos professores e seus saberes está evidente e em grande discussão em diversos países, e especialmente na América do Norte. Seu trabalho, bem mais modesto, não teve a mesma difusão dos outros dois, porém constitui do mesmo modo uma contribuição interessante pelo esforço de construir uma tipologia das pesquisas.

Em linhas gerais, o mesmo objetivo de Martin pode ser identificado no trabalho de Gauthier et al. (1998), ${ }^{5}$ terceira síntese a ser apresentada. Estes autores também estão preocupados com a natureza dos saberes, mas a idéia central que os alimenta é mais ambiciosa. Eles pretendem dar conta do problema relativo a um repertório de conhecimentos, presente nas pesquisas sobre o knowledge base, assumindo uma posição de crítica às abordagens desenvolvidas pelos pesquisadores americanos. O contexto de sua obra é o de internacionalização das reformas do ensino e da formação dos professores, e da explosão da problemática saberes, ela própria.

Das três sínteses norte-americanas trazidas para esta reflexão, o trabalho de maior repercussão sem sombra de dúvida é o de Shulman (1986a). Seu objetivo é mapear os diferentes programas de pesquisa sobre o ensino e suas respectivas abordagens e, também, indicar perspectivas futuras para a pesquisa, considerando as lacunas observadas nos programas anteriores. Tarefa que, segundo ele, requer um esforço no sentido de compreender o contexto no qual as pesquisas são geradas; a direção na qual são formulados os questionamentos e de que forma são estruturados (conceitual e metodologicamente); as abordagens utilizadas e as polêmicas presentes no âmbito da comunidade de cientistas.

Cinco são os programas de pesquisa sobre o ensino e sobre a docência identificados pelo autor: as pesquisas processo-produto, que correlacionam a performance dos docentes e as capacidades subseqüentes adquiridas pelos alunos; o programa Academic learning time, que vincula a performance do docente com o tempo de aprendizagem dos alunos; o programa sobre a cognição dos alunos, que também faz relação com as ações do docente; o Classroom ecology, que examina as influências reflexivas das ações dos docentes e dos estudantes, em re- 
lação às quais busca-se o esclarecimento através de aspectos do pensamento dos atores; e o programa sobre a cognição dos professores, que examina os pensamentos dos docentes em relação às suas ações. Um sexto programa, desenvolvido pelo próprio Shulman, em oposição aos anteriores e procurando preencher as lacunas dos mesmos, é apresentado no final de sua exposição.

A abordagem processo-produto constitui o mais importante e vigoroso programa de pesquisa desenvolvido desde os anos de 1950. Entre os principais autores que contribuíram para o seu desenvolvimento estão Mitzel (1960), Dunkin e Bidlen (1974), Gage (1978), Soar e Soar (1979), Brophy (1983), Evertson et al. (1983), Brophy e Good (1983), entre outros citados por Shulman (1986a). O programa tem por objetivo, de maneira geral, analisar os efeitos das ações dos docentes, ou das performances destes durante o ensino, sobre a aprendizagem dos alunos. Com base na análise das variáveis implicadas no processo, procurava estabelecer uma correlação entre as diferentes performances no ensino, "os processos", e as diferenças de aprendizagem dos alunos, "os produtos".

Centrada em estudos empíricos realizados no contexto da sala de aula, durante diferentes períodos do ano escolar, a abordagem processoproduto se desenvolve em um contexto extremamente propício: ela é compatível com a forte tradição da psicologia behaviorista aplicada, já bem estabelecida em outros campos profissionais; ao mesmo tempo, ela se contrapõe aos estudos de laboratório, largamente utilizados pela psicologia behaviorista, transpondo esse programa para o meio natural, a sala de aula. Seus resultados são vistos como mais concretos, generalizáveis e imediatamente aplicáveis à prática e ao desenvolvimento de políticas e de reformas; e por fim, os professores parecem capazes de apreender a agir tal qual os resultados sugeridos pelo programa de pesquisa, o que conseqüentemente repercutiria na aprendizagem dos alunos e na melhoria das escolas. O central dessa abordagem é o comportamento eficaz do professor e a eficácia do ensino, medidos por meio de testes estandardizados do rendimento dos alunos.

O segundo programa de pesquisa analisado por Shulman, o Academic learning time, aparece como uma variação do anterior em decorrência das fragilidades do primeiro e aponta os indicadores da eficácia do ensino, ou seja, mostra porque alguns comportamentos são eficazes. O programa procurava apontar os elementos "mediadores-chave" entre as condutas dos professores e as atividades dos alunos, durante o ensino, antes mesmo da realização dos testes de final de ano. Além 
disso, tinha por meta dar relevo às complexidades que envolvem as interações em classe no desenvolvimento das tarefas, visando captar mais sensivelmente os efeitos do processo de ensino propriamente dito que o resultado final, obtido através dos testes de performance. O programa, que se desenvolve a partir dos trabalhos de Berliner (1979) e sua equipe, baseia-se fundamentalmente no modelo de aprendizagem de Carroll (1963), no qual o tempo aparece como elemento central da relação entre ensino e aprendizagem. Embora tentasse superar o programa anterior, o Academic learning time continuou a empregar os mesmos métodos das pesquisas processo-produto como, por exemplo, ênfase nos estudo das variáveis; foco centrado nos processos dedutivos do pensamento dos alunos; visão de estudante mais afinada com a idéia de uma unidade de análise individual que coletiva; concepção passiva da aprendizagem e não incorporação dos eventos da vida na sala de aula.

O terceiro programa, Students mediation, vai centrar-se sobre o conhecimento dos alunos, tendo em conta a intervenção dos docentes. Através de influências da psicologia cognitiva, da psicologia da personalidade, do conceito do eu, dos estudos da cognição social e da contribuição da sociologia, seja na formulação teórica ou na escolha dos métodos, este programa faz uma ponte entre as pesquisas dos programas anteriores e as pesquisas dos programas subseqüentes. Ele é um intermediário entre as pesquisas de tradição psicológica quantitativa, processo-produto e Academic learning time, e as estratégias qualitativas que vão predominar no programa Classroom ecology vinculado à sociolingüística e à etnografia. As contribuições do antropólogo Geertz (1973) e do psicólogo dos processos de informação Simon (1953) estão na base da mediação entre o social e o cognitivo. Um estudo clássico nessa linha é o de Mehan (1979), o qual analisa a complexidade da vida em sala de aula para os estudantes, que é marcada por um duplo contrato: a integração dos conhecimentos acadêmicos e do conhecimento social ou interacional. O programa vai enfatizar também aquilo que os estudantes pensam e sentem e as motivações em torno das atividades em sala de aula. Um outro estudo importante, por reunir os processos social e intelectual na análise do ensino aprendizagem, é o de Doyle (1983), focalizando as dificuldades cognitivas dos alunos e o desafio para levar a cabo as atividades de sala de aula e um dado meio social e avaliativo. Tanto do lado da psicologia, como da antropologia social, a questão central é qual sentido ao ensino é dado pelos estudantes em relação aos eventos passados na sala de aula.

Os três programas anteriores, de acordo com Shulman (1986a), compartilham da mesma tradição das pesquisas processo-produto e, com 
exceção da corrente da percepção social, derivam da psicologia. Já o Classrom ecology é oriundo da antropologia, da sociologia e da lingüística e vai ancorar-se mais em uma metodologia qualitativa que quantitativa. Com base na antropologia, investiga-se o sentido que os atores dão às suas ações (Geertz, 1973). A preocupação não é acumular conhecimentos sobre comportamentos e práticas eficazes, para guiar as práticas educativas, mas constituir-se como uma fonte de crítica e de problematização do ensino. Os representantes desse programa são oriundos de diferentes tradições disciplinares como a etnografia (Ericson, 1973; Health, 1983; Wolcolt, 1973; Philips, 1983); a sociologia (Delamont e Atkinson, 1980; Lightfoot, 1983), a psicologia (Jackson, 1968; Smith e Geoffrey, 1968), sociolingüística (Cazden, 1986; Mehan, 1979; Green, 1983) e especialistas do ensino (Doyle, 1977). Seu objetivo central é extrair o sentido que os estudantes e os docentes dão às suas ações, ao ensino propriamente dito. A sala de aula inserida em um contexto mais amplo, por exemplo a comunidade, é vista como um ecossistema, um espaço organizado social e culturalmente, um lugar de comunicação e interações construídas cotidianamente. Segundo Hamilton (1983 apud Shulman, 1986), quatro são os critérios de referência da abordagem ecológica: primeiro, atenção aos eventos em classe, às interações entre as pessoas e seus respectivos meios, porém em reciprocidade e não a partir de uma perspectiva de causalidade; segundo, compreensão do processo ensino-aprendizagem como um continuum de interações sem a pretensão de isolar determinados fatores buscando suas causas e efeitos; terceiro, visão da sala de aula inserida no contexto mais amplo da escola, da comunidade, da cultura, da sociedade etc.; quarto, observação daquilo que não é evidente, como os pensamentos, os sentimentos, as atitudes etc. dos agentes em sala de aula.

O quinto programa focaliza o conhecimento dos docentes; a ênfase que antes era sobre o que fazem os docentes, passa a ser o conhecimento dos professores, ou seja, como suas ações estão ligadas às ações dos estudantes e como o professor pode ser melhor preparado. A base não é mais a psicologia behaviorista, mas a psicologia cognitiva de Piaget (esquemas de pensamento) e a psicologia da informação (informationprocessing), e também a psicolingüística. Destacam-se nesse programa os trabalhos de Shavelson (1973), Shulman e Elstein (1975), Elbaz (1981), Shavelson (1983), Leinhardt (1983) e Anderson e Smith (1984). O professor é visto como profissional dotado de razão, um ator que toma decisões, faz julgamentos, no contexto complexo e incerto da sala de aula. Suas ações são guiadas por pensamentos, julgamentos e decisões. De modo 
que os processos cognitivos do docente são o objeto a ser estudado (tanto no momento de planifição como no da ação e das interações em classe) e a metodologia empregada envolve técnicas de reflexão em voz alta, estimulação da memória, observações. Dentro desse programa, o trabaIho de Elbaz é salientado por centrar-se no conhecimento prático dos professores, no qual o autor desenvolve uma teoria sobre o conhecimento prático pedagógico dos professores de acordo com as observações e as entrevistas.

O sexto programa, cujo esboço aparece delineado ao final da análise dos cinco anteriores, é do próprio Shulman. Segundo o autor, o que falta nos programas anteriores é um esclarecimento da compreensão cognitiva dos conteúdos das matérias ensinadas, e das relações entre estes conteúdos e o ensino (instruction) propriamente dito que os docentes fornecem aos alunos. Qual conhecimento da matéria ensinada os professores têm em sua mente? Junto com sua equipe, ele vai desenvolver um intenso trabalho de pesquisa, identificando, então, três tipos de conhecimentos que possuem os docentes: o conhecimento da matéria ensinada (subject knowledge matter), o conhecimento pedagógico da matéria (pedagogical knowledge matter) e o conhecimento curricular (curricular knowledge) (Shulman, Sykes e Phillips, 1983, Shulman, 1986a, 1986b, 1987). Seus estudos de natureza pedagógica vão consolidar a corrente do knowledge base/base de connaissances, numa perspectiva compreensiva da cognição e das ações dos docentes quanto ao desenvolvimento de projetos, atividades, teorias implícitas e explícitas que eles utilizam em seu trabalho, concepções sobre a matéria ensinada, currículo e programa etc.

Até então, com Shulman (1986a), tem-se uma idéia dos programas que orientaram as pesquisas sobre o ensino e a docência e é devido à sua própria pesquisa que se viu sinalizada a temática dos saberes dos docentes. Mesmo se o tema conhecimento já vinha sendo relevado nas outras pesquisas, é com os estudos sobre a cognição dos docentes, com a volta ao ator - ou seja, o professor - como sujeito das ações, e mais adiante com a crise das profissões, com o movimento pela profissionalização, com as grandes reformas educativas nos Estados Unidos, que observamos esse tema aflorar e expandir-se rapidamente. Assim que, as sínteses que se seguem já trazem as influências desse novo contexto e buscam, cada uma ao seu modo, traçar um panorama das abordagens que vão, em diferentes momentos, orientar a pesquisa sobre os saberes dos docentes.

A segunda síntese que passo a apresentar, a de Martin (1992), analisa a pluralidade metodológica das pesquisas norte-americanas sobre os 
professores e seus saberes e propõe um reagrupamento dos estudos segundo a natureza dos saberes docentes. Segundo este autor, é possível identificar quatro abordagens teórico-metodológicas distintas: uma psicocognitiva, que enfatiza a estruturação mental dos saberes; uma subjetivainterpretativa, que focaliza as dimensões fenomenológica e interacionista dos saberes docentes; uma curricular, que investiga a transformação dos saberes a ensinar no contexto da sala de aula; e uma profissional, onde o saber docente é tomado a partir das deliberações do próprio sujeito, o professor. Vê-se logo de saída que Martin não inclui as pesquisas processo-produto, o que é explicável uma vez que estas não estão preocupadas com os saberes dos docentes e sim com os efeitos de suas ações; além disso, a problematização do ensino dentro dessa perspectiva passava mais pelo que devem saber os docentes, ou para ser mais exata, pelo como devem agir os docentes, do que pelo questionamento daquilo que sabem os professores. Mas será que é possível identificar uma visão dos conhecimentos dos professores em se tratando da abordagem processoproduto? Deixarei essa questão em suspenso e a retomarei ao discutir o problema das tipologias. Voltemos à classificação de Martin.

A primeira abordagem, a psico-cognitiva, ressalta a estruturação mental dos saberes e sua aplicação no contexto concreto da sala de aula. Estes estudos, segundo ele, foram recenseados por diversos autores (como Clark e Yinger, 1977, 1987; Shavelson e Stein, 1981; Calderhead, 1981; Clark e Paterson, 1986; Borko et al., 1990 apud Martin, 1992; etc.). Basicamente, as pesquisas buscavam pôr em evidência as diferenças entre os docentes experientes e os novatos, constatando que os últimos baseiam sua prática em esquemas de ação mais estruturados. Os professores experientes possuem um repertório maior de rotinas em classe, o que lhes permite se adaptarem mais rápida e facilmente às diferentes situações exigidas pelo cotidiano de trabalho. $O$ interesse dos pesquisadores é pela rede de estruturas ou repertório de conhecimentos, das rotinas e das ações vividas em sala de aula, que se complexificam com o tempo, a partir das experiências passadas, num processo de construção e reconstrução das estruturas mentais.

A segunda, a subjetiva-interpretativa, acentua aspectos fenomenológicos e simbólicos dos saberes. Busca evidenciar a relação subjetiva que o docente estabelece com as diversas facetas de seu trabalho e como essa relação intervém na constituição dos saberes e no exercício da prática docente. Estes trabalhos, num sentido mais amplo, vão se apoiar na etnometodologia, com entrevistas estruturadas e observação participante. O contexto, a situação, na qual são gerados os saberes e as práticas, ganham relevo nas análises. Alguns estudos, como os de Elbaz (1983) e Clandinin 
(1986), segundo Martin, constituem exemplos clássicos desse tipo de abordagem, na qual os saberes são identificados com as imagens que o professor tem da prática docente. Essa imagem é atravessada pelas idiossincrasias, valores, emoções e necessidades experimentadas pelo sujeito. Estão inseridos nesse grupo, os estudos que focalizam as imagens, como metáforas, através da ênfase em uma metodologia que valoriza a fala, a linguagem, mais que a situação; os trabalhos que se interessam pela biografia dos docentes e por suas histórias de vida, tentando compreender a relação entre o sujeito, sua história e as situações de trabalho; os estudos que procuram captar a noção de "imagem desenvolvida" pelos docentes novatos ou estagiários em suas primeiras experiências de ensino, suas pré-concepções em contraponto com as interações profissionais em situação de sala de aula; e, ainda, as pesquisas que se reclamam interacionistas-simbólicas e que acompanham os estudantes em estágio. O central na abordagem subjetiva-interpretativa é que ela representa o saber docente como um conjunto de saberes objetivos e formais, porém, constituídos de relações subjetivas que os docentes mantêm com a sua prática, os saberes são moldados por relações qualitativamente diferentes: morais, críticas, emancipatórias, estéticas, valorativas, afetivas etc.

A terceira, a curricular, examina em que os "saberes proposicionais" e os "saberes institucionalizados" contribuem para moldar a prática, ou seja, como os conhecimentos ligados ao ensino, aos conteúdos disciplinares, aos programas, ao currículo etc. repercutem na ação docente, mas também como os professores operam com esses conhecimentos em classe. Pela tipologia que oferece, um dos trabalhos destacados é o de Shulman (1987), no qual são identificadas sete categorias de saberes: o conhecimento disciplinar, o conhecimento pedagógico geral, o conhecimento do currículo, o conhecimento da psicologia da infância, o conhecimento do contexto institucional, os conhecimentos dos fins educativos e outros conhecimentos que não fazem parte do domínio escolar. Estes saberes se consolidam em um amálgama pedagógico que une conteúdo e pedagogia. Outros estudos apresentados por Martin, seguindo essa mesma linha, chegam a enfatizar que, se existe um saber docente, este é o curricular, afinal se existe um saber indispensável ao professor, trata-se do saber dos conteúdos que ele ensina, mesmo tomando-se em conta que um docente deve conhecer seus alunos e suas condições sociais etc.

A quarta abordagem, a profissional, está assentada sobre a idéia de que os professores são produtores de saberes e que existe um saber que emerge da prática profissional. De acordo com Martin (1992), trabalhos como os de Felman-Nemser (1990) e de Schön (1983) investem na idéia 
de que os professores desenvolvem um saber prático, diante da imprevisibilidade e ambigüidade da prática, o que exige do docente uma capacidade artística, de invenção, de adaptação à realidade do ensino que, por sua vez, é dinâmica e se encontra em constante transformação. E estudos como os de Hammersley (1984), Nias (1984), Belenky (1986) põem em evidência as interações que os professores estabelecem com seus pares e com seus alunos. Essas interações, desenvolvidas por meio de uma forma de comunicação sútil e privada, são ricas em informações, em trocas, em intercâmbio de macetes e truques da profissão. Para Martin, se isso é verdade, se enquadram nesse quarto grupo, as idéias de Tardif et al. (1991), que sustentam que, pelas interações, os professores produzem e tentam produzir saberes que lhes permitem dominar e compreender a sua prática. Outros estudos que também apostam na idéia de que existem saberes que nascem da e na prática (trata-se da corrente da prática reflexiva, reflexif practitionner, praticien réflexif), mesmo emanando de conceitualizações e proposições teóricas diferentes, foram agrupados junto à abordagem profissional. Só para citar alguns, figuram entre eles os trabaIhos de Schön (1983, 1987); Calderhead, (1989); Houston e Clift (1990); Grimmet et al. (1990); Gore e Zeichner (1991) etc. Nessa mesma linha, Martin (1992) acrescenta a pesquisa-ação (action research, rechercheaction), através de Stenhouse e Elliot que, não muito longe das idéias encontradas em Schön, afirmam que o docente desenvolve o seu saber através da investigação sistemática da sua própria prática, e, ainda, a corrente do professor como pesquisador, teachers as researcher, que particulariza o papel crucial do professor pesquisador, o qual produz um saber personalizado e, até certo ponto, inacessível, em uma perspectiva ética, ao pesquisador externo. Esse dilema entre o ponto de vista do professor investigador e o investigador externo, Martin considera ser bem analisado por Cochran-Smith e Life (1990), contudo ele próprio questiona: Como essa visão pode ajudar a fazer emergir um saber que se supõe sem vocabulário e sem história? Martin não responde a essa questão e termina sua análise advertindo os pesquisadores quanto à necessidade de se ter em conta a pluralidade no campo. Passemos então à terceira síntese.

De grande envergadura, o trabalho de Gauthier et al. (1998) oferece uma boa descrição das pesquisas norte-americanas sobre o que ficou conhecido na América do Norte como knowledge base (ou base de connaisssances). Os autores analisam as investigações centradas na natureza dos saberes subjacentes ao ato de ensinar, mais precisamente, os estudos sobre o ensino que buscam identificar e/ou definir um repertório de conhecimentos dos docentes. Sua singularidade consiste em ser um estu- 
do síntese que procura não somente identificar o corpus das pesquisas realizadas nas salas de aula nas últimas décadas, mas os conhecimentos, relativamente aos saberes dos professores, extraídos dessas pesquisas.

Uma outra particularidade é que seus autores procuram situar suas análises no âmbito de uma problemática mais ampla. Explorando uma literatura internacional sobre o tema, buscam enfatizar, inicialmente, os desafios de um ofício cujo corpus de saberes é de difícil apreensão; exploram os problemas relativamente à determinação de um repertório de conhecimentos específicos do ensino; procuram definir a "pedagogia" e apresentam um modelo de análise para a mesma; por fim, traçam um panorama da evolução das pesquisas sobre a eficácia no ensino, visando extrair elementos que possam contribuir para a edificação de um repertório de saberes. Antes de mergulharem nas pesquisas propriamente ditas, expõem os pilares de uma teoria da pedagogia; e, ainda, explicitam a concepção de saberes que defendem. Como se pode ver, trata-se de um trabalho ambicioso que mereceria maiores comentários, porém, vou ater-me no que interessa para este artigo, as classificações que esses autores fazem das pesquisas sobre o ensino.

Segundo Gauthier et al. (1998) são três os paradigmas das pesquisas sobre o ensino: ${ }^{7}$ o enfoque processo-produto, o enfoque cognitivista e o enfoque interacionista-subjetivista. $O$ primeiro, processo-produto, já mencionado neste artigo dentro da análise de Shulman (1986a), no âmbito dos estudos sobre os saberes docentes, releva o problema de que, nesse tipo de enfoque, o professor é visto apenas como um gestor de comportamentos que deve organizar (da melhor forma, buscando a eficácia) os processos de ensino, visando a aprendizagem dos alunos. As interações, o contexto, os outros saberes que não sejam aqueles relacionados aos conteúdos e aos procedimentos de ensino, o próprio conteúdo de uma certa forma, os aspectos subjetivos da relação professor-aluno, entre outros, ficam obscurecidos por um conjunto de variáveis comportamentais do professor e seus "efeitos imediatos" sobre os alunos.

O segundo é o cognitivista, que se desenvolveu principalmente nas duas últimas décadas. Ainda que a abordagem centrada nos aspectos cognitivos, no pensamento e na construção dos esquemas de pensamento remonte a Piaget e Vigotski e, também, que constitua um vasto campo de pesquisa com inúmeras variantes, tanto do lado europeu como americano do norte, o que Gauthier e seus colaboradores buscam evidenciar são os estudos que vieram a constituir as chamadas "ciências da cognição", ocupando o cenário norte-americano, a partir dos anos de 
1970. Entre estes, no caso das pesquisas sobre o ensino, ressaltam os estudos sobre o pensamento dos professores, teachers thinking, os quais se situam mais próximos da fenomenologia e cuja orientação incorpora a complexidade do ofício docente, admitindo que o professor utiliza conhecimentos contextualizados, interativos e especulativos. Mas o central da abordagem cognitivista para o estudo dos saberes docentes, dentro da perspectiva das ciências da cognição, é, segundo os autores, a sua preocupação com o processamento da informação e com os processos de construção do conhecimento dentro do complexo processo ensinoaprendizagem. Além disso, essa perspectiva trabalha com o conceito de "metacognição", que envolve o conhecimento e o controle das estratégias cognitivas. Entretanto, essa abordagem também é clivada de reducionismos, a começar por tratar aspectos humanos e simbólicos como fenômenos naturais e, sobretudo, por introduzir toda uma forma de compreender os fenômenos da cognição muito próxima dos campos da administração e da informática. Daí, a ênfase na terminologia: eficiência, competência, rentabilidade, medida, controle, planejamento, entre outros.

O terceiro enfoque, interacionista-subjetivista, segundo Gauthier e seus colaboradores, reúne o interacionismo simbólico, a etnometodologia, a etnografia escolar, a sociolingüística e o enfoque ecológico. No bojo desta abordagem, uma vez que cada corrente apresentará suas particularidades, consideram os trabalhos que têm referência na fenomenologia e que dão ênfase ao indivíduo, compreendido com um sujeito portador "de histórias", ou seja, um ser que constrói o mundo em relação com outros sujeitos. Nessa perspectiva, o ensino é concebido com uma forma de interação simbólica, um processo no qual os sujeitos agem em função daquilo que os conhecimentos significam para eles. Em decorrência disso, para conhecer os significados construídos pelos sujeitos, é necessário, também, ter em conta o contexto no qual eles interagem. Do ponto de vista dos estudos sobre os saberes, como já havia sublinhado Martin (1992), o foco repousa nas representações que os professores têm dos seus saberes e nas interações que estes estabelecem em classe.

Ainda de acordo com Gauthier et al. (1998), o interacionismosubjetivista, na versão fenomenológica, enfatiza a análise das experiências individuais e o conhecimento adquirido pelo indivíduo através das suas experiências; na versão etnometodológica, vai buscar compreender como os indivíduos dão sentido ao mundo e como realizam as ações cotidianas; na visão etnográfica, vai focalizar a dinâmica da sala de aula e tentar compreendê-la, bem como as representações do professor e dos alunos nas interações cotidianas; na visão ecológica, vai tentar construir 
um modelo explicativo, coerente, de funcionamento da sala de aula, a fim de compreender a eficiência dos professores e seus saberes; e, na visão sociolingüística, embora os autores a tenham deixado de fora de sua apresentação, vai acentuar a linguagem, os aspectos relativos à verbalização dos sujeitos sobre os seus saberes.

Feita a apresentação das três sínteses, passo à indicação de alguns pontos que podemos extrair das mesmas, visando o desenvolvimento futuro das pesquisas sobre os saberes docentes.

\section{O problema das tipologias e a amplitude de um tema mundial}

Na seção anterior, optei por apresentar três contribuições que procuram agrupar, a partir de diferentes tipologias, os estudos sobre o ensino e sobre a problemática dos saberes docentes. Nesta seção buscarei pôr em evidência alguns pontos relativamente ao problema das tipologias.

Um primeiro ponto a ser destacado diz respeito à dificuldade enfrentada por aqueles que se propõem a realizar sínteses para lidar com a diversidade conceitual e metodológica do campo. Isto porque os estudos analisados pelos autores são filiados a diferentes tradições teóricometodológicas. Essa diversidade, como ressaltou Martin (1992), apoiando-se em Shulman (1986a), pode ser vista, por um lado, como um aspecto de maturidade do campo; porém, é preciso reconhecer que ela também pode ser encarada como um aspecto de nebulosidade, por outro, impedindo uma conceptualização mais refinada do objeto estudado. Meu intuito aqui foi, concordando com Shulman (1996a) e Martin (1992), dar luzes à diversidade teórico-metodológica das pesquisas, reconhecendo as contribuições destas para o campo educacional, não pela sua complementaridade ou por sua singularidade enquanto paradigmas, abordagens ou enfoques concorrentes, mas pelas diferentes formas de encarar e investigar o fenômeno educativo.

Um segundo ponto decorre das próprias tipologias extraídas das sínteses apresentadas. Observo que elas também são marcadas pela diversidade teórica e metodológica, uma vez que os agrupamentos e classificação das pesquisas obedecem a critérios diferenciados. Gauthier et al. (1998), por exemplo, consideram que a classificação apresentada por Martin (1992) falha em misturar dois enfoques que têm origem em bases epistemológicas (o cognitivo e o subjetivo-interpretativo) com dois outros que se apóiam em um tipo de objeto de estudo (o curricular e o da profissionalização), o que significa, nos dizeres dos autores, "misturar 
maçãs com laranjas", e que para mim não consiste necessariamente numa falha, mas num dilema que é do próprio do campo. Nessa mesma linha, constato que os critérios de Shulman (1986a) estão enraizados no seu objetivo principal, que é a demarcação dos principais programas que marcaram a pesquisa sobre o ensino e os docentes; além disso, a problemática dos saberes docentes ainda é embrionária e faz parte das pesquisas do autor em andamento naquele período.

Um terceiro ponto diz respeito à diversidade empírica dos próprios objetos de pesquisa. As três sínteses pretendem dar conta da diversidade das pesquisas empíricas, ao menos esse é o objetivo explícito de Shulman (1986a) e de Gauthier et al. (1998). Todavia, os objetos empíricos de pesquisa são extremamente variados; por exemplo, alguns pesquisadores estudam as representações, as crenças, as regras de ação social, os comportamentos etc. A esse propósito, retomo, por exemplo, o questionamento anterior em relação à ausência das pesquisas processo-produto na síntese de Martin. Ora, as pesquisas do tipo processo-produto, que são umas das abordagens mais importantes, profícuas e polêmicas da pesquisas sobre o ensino (Shulman, 1986), não se interessam pela questão dos saberes docentes e sim pelo comportamento eficaz do professor. Isso parece responder à minha questão e, caso se considere que elas possuem uma visão dos saberes dos docentes, devemos observar, nesse caso, que se trata de um olhar que vê o conhecimento do professor como algo que está fora dele e não como alguma coisa que está com e no professor.

Um quarto ponto refere-se ao grau de abstração desses estudos, que terminam por constituir um discurso dos e entre os pesquisadores, cada vez mais distante da realidade dos docentes. Por exemplo, a tipologia apresentada por Clermont et al. (1998) é estruturada de acordo com uma síntese das sínteses de pesquisa e seus critérios para construir sua tipologia. E muito pouco tem a ver com os critérios dos pesquisadores que estão na base dos dados de sua síntese, ou seja, seus critérios estão muito distantes das questões que se colocavam os pesquisadores trabalhando com os docentes nas escolas. Muitas das pesquisas recenseadas pelos autores em sua síntese, portanto, não têm como horizonte a questão dos saberes dos docentes, como já destaquei em relação às pesquisas processo-produto. Para quem pretendia extrair das pesquisas conhecimentos válidos que pudessem contribuir para um repertório de conhecimentos docentes, trata-se de um problema a ser equacionado. E, ainda que os autores no decorrer de sua obra busquem definir critérios de validação da pesquisa sobre o ensino e apelem à razão pedagógica do professor e à utilização prudente em relação à apli- 
cação dos conhecimentos oriundos das pesquisas, não me parece evidente a superação dessa questão.

Um quinto ponto está relacionado com a utilidade das sínteses para o desenvolvimento da pesquisa. Mesmo considerando que elas possuem suas limitações, nós devemos admitir que as sínteses têm um papel histórico importante para o desenvolvimento do campo educacional, principalmente a de Shulman (1986a), que é produzida com um sentido explícito de organização do campo e de redirecionamento das questões até então tratadas nas pesquisas; além disso, seu trabalho busca servir de guia para os pesquisadores, sinalizando as pesquisas pertinentes e válidas para o ensino. O que gera um problema a respeito dos critérios utilizados para considerar um estudo válido ou não, mas essa questão ficará para uma reflexão posterior.

Contudo, um sexto ponto a ser sublinhado refere-se à repercussão dessas tipologias em países como o Brasil. O fato dos ecos das mesmas serem sentidos em vários países não é um problema, além disso, trata-se de um movimento inevitável. Nos últimos anos, temos vivido experiências similares no âmbito da formação dos professores, das pesquisas e do discurso educacional, das políticas educativas etc., em vários países (Lessard et al., 1998). O que distingue uma nação de outra é o grau de avanço, implantação, implementação, avaliação etc. desses discursos e práticas, bem como a forma como estes se difundem e são incorporados pelas instituições e agentes sociais. Acrescentando-se a isso, evidentemente, o próprio desenvolvimento social, político, econômico, cultural etc. de cada país que está na base dos interesses e desafios sociais. Sob essa ótica, a repercussão não é em si um aspecto negativo, problemática é a forma de transferibilidade que ela assume. Por exemplo, importam-se problemas, questões, metodologias que, em alguns casos, muito pouco têm a ver com as questões e dilemas educacionais presentes em nossa sociedade e que, além disso, consistem em temas marcados pelas disputas política e científica que permeiam a sociedade americana e o contexto das grandes reformas educativas lá desenvolvidas. Os estudos processo-produto sobre o comportamento eficaz do professor, os estudos sobre a cognição e sobre o pensamento dos professores, sobre a profissionalização dos docentes, entre outros, por vezes, foram utilizados pelos pesquisadores e políticos educacionais brasileiros, sobrepondo-se aos desafios reais da prática concreta dos professores nas escolas e, também, à própria originalidade dos temas emergentes que estes atravessam tanto na educação de um modo geral, como na formação de professores em particular em nossa sociedade.

Recebido para publicação em 16 de janeiro de 2001. 


\section{Notas}

1. Uma pesquisa bibliográfica com a ajuda das palavras-chave teacher and knowledge, na base americana ERIC, por exemplo, nos fornece mais de 21 mil referências sobre esse tema e repertoria 300 Handbooks.

2. O relatório Tomorrow's teachers, do Grupo Holmes, é produzido por representantes de faculdades e colégios pertencentes a universidades de pesquisa. $A$ Nation prepared: Teachers for 21st Century, do Carnegie task force on teaching as a profession, é produzido por um grupo formado por autoridades pertencentes ao alto escalão da função pública, do mundo dos negócios, da educação, do sindicalismo docente.

3. Lee S. Shulman é presidente da Carnegie Foundation for the Advancement of Teaching, instituição de pesquisa e centro político responsável pelo incremento dos colleges e escolas americanas. Ele também é professor da Charles E. Ducommun e da Universidade Stanford.(http://depts.washington.edu/cidrweb/C 1997 Center for Instructional Development and Research, University of Washington).

4. Daniel Martin é professor na Universidade do Quebec (Canadá) em AbitibiTéminscamigue.

5. Clermont Gauthier é professor titular na Faculdade de Ciências da Educação, na Universidade Laval.

6. Os autores preferem o termo pedagogia a ensino ou didática. Embora em boa parte do livro façam referência às pesquisas sobre o ensino, após buscar conceptualizar os termos educação, pedagogia, ensino, didática e instrução, optam pelo termo pedagogia, envolvendo, segundo eles, as duas dimensões fundamentais do ensino, ou o duplo programa do professor: o ensino dos conteúdos e a gestão da classe (Gauthier et al., 1998).

7. Essa tipologia tem por base o trabalho de Martineu, Gauthieur e Tardif (1994), intitulado: Analise critique de paradigmes de recherche sur les savoirs enseignants. 62ำ Congrès de l'ACFAS, Montreal/Québec, 1994.

\section{Teacher KNOWLEDGE: SOME TYPOLOGIES AND CLASSIFICATIONS ABOUT A FIELD OF RESEARCH}

ABSTRACT: The purpose of this article is to discuss some typologies and classifications about research on teaching, teachers and teacher knowledge. Three major synthesis of research are analyzed. They propose a categorization of studies conducted in these areas on these subjects and bring to light as well the variety diversity of research traditions, of the currents of search as the theoretical and methodological contexts in which the studies were produced. In conclusion, limits and possibilities of this research literature are discussed.

Key words: teacher's knowledge, knowledge, teaching, teacher's education. 


\section{Referências bibliográficas}

GAGE, N.L.Paradigms for research on teaching. In: GAGE, N.L. (org.). Handbook of research on teaching. A Project of the American Educational Research Association. Chicago: Rand McNally, 1963.

GAUTHIER C. et al. Por uma teoria da pedagogia. Ijuí: Unijuí, 1998. 457p.

LESSARD, C. Étude réalisée pour l'Adereq. Montréal, 1999 (mimeo).

DOYLE, W. Paradigms for research on teacher effectiveness. In: SHULMAN L. S. (dir.), Review of research on education vol. 5, Itasca: F.E. Peacock, 1977, p. 163-199.

HOUSTON, W.R.; HABERMAN, M. e SIKULA, J. (orgs.). Handbook of research on teacher education. New York: MacMillan, 1990.

MARTIN, D. Nature du savoir enseignant: Analyse des écrits anglo-saxons. In: MAINGUY E. et al. Compétence et formation des enseignants. Publication des Sciences de l'Éducation, Trois-Rivières, 1993, p. 289-304.

MARTIN, D. Formation professionnelle en éducation et savoirs enseignants: Analyse et bilan des écrits anglo-saxons. Communication présentée au premier Colloque de l'AQUFOM, Université du Québec à TroisRivières, nov. 1992.

SIKULA, J.; BUTTERY, T.J. e GUYTON, E. (orgs.). Handbook of research on teacher education. $2^{e}$ ed. New York: Macmillan, 1996.

SHULMAN, L. Knowledge and teaching: Foundations of the new reform. Harvard Educational Review oㅜ 1, vol. 57, febr.1987, p. 1-22.

Paradigms and researcher programs in the study of teaching: A contemporary perspective. In: WITTROCK, M.C. (org.) Handbook of research on teaching. 3ㄹ ed. New York: MacMillan, 1986a, p. 3-36.

Those who understand: Knowledge growth in teaching. Educational Researcher $\mathrm{n}^{\circ}$ 2, vol. 15, Washington, febr. 1986b, p. 4-14.

TARDIF, M., LESSARD, C. e GAUTHIER, C. Formation de maîtres et contextes sociaux. Paris: Presse Universitaire de France, 1998. 290p.

TARDIF, M. e LESSARD, C. Travail enseignant au quotidien. Québec: Ulaval, 1999. 575p. 